\title{
I migração haitiana e a relação com comunicação, consumo e trabalho
}

\author{
Cristóvão Domingos de Almeida*
}

\section{1 - Introdução}

A comunicação se relaciona com as grandes transformações que experimentamos na contemporaneidade. Para Baccega (2015), as inter-relações entre comunicação e a sociedade de consumo são vetores centrais da atualidade. Ariztía (2016, p. 17) complementa essa ideia ao afirmar que "a expansão do consumo mostra-se geralmente como o principal indicador da expansão dos mercados na vida social".

É nesse espaço de interações, escolhas e diálogo que pode ser compreendido o argumento de Thompson (1998, p. 36) "[...] sem a comunicação cada pessoa seria um mundo fechado a si mesmo. Pela comunicação as pessoas compartilham experiências, ideias e sentimentos".

É importante superar a noção de uma comunicação determinista e passiva. Ela não pode ser compreendida apenas como transferência de informações, de dados, de experiências e de práticas comunicacionais entre os sujeitos. Ou seja, a comunicação não deve ser mecânica e nem instrumental, mas ela está envolvida na própria dinâmica das relações humanas, no cotidiano dos sujeitos e nas escolhas e decisões nos espaços de consumo. Por isso, Baccega (2013) denomina a contemporaneidade como a era da comunicação e do consumo, considerando as duas dimensões como formadoras de um todo, indivisível e interdependente.

Neste artigo, aprofundaremos essas dimensões articulando-as com o conceito de migrações e trabalho, identificaremos as classificações do trabalho precarizado pelo viés da informalidade, pelos quais os imigrantes haitianos vivenciam no seu cotidiano. Além disso, destacaremos as mobilizações e as articulações, através das plataformas digitais, para superar essas situações de desvalorização da força vital, da exploração e dos processos de dominação, garantindo acesso ao trabalho, que auxilia na permanência e na sobrevivência dos imigrantes.

\footnotetext{
* Pós-doutor em Comunicação e Práticas de Consumo (ESPM), doutor em Comunicação e Informação (UFRGS), mestre em Educação (Unisinos) e graduado em Relações Públicas (PucCampinas). É professor da Universidade Federal do Pampa.

Contato: cristovaoalmeida@gmail.com
} 
Na construção deste artigo realizamos observação in loco na cidade de São Paulo, na Missão Paz, organização social que acolhe imigrantes. Além disso, nos baseamos nos levantamentos bibliográficos e nas entrevistas em profundidade para compreender expectativas, o consumo de mídia e o acesso ao mundo do trabalho, enquanto garantias de condições de vida em solo brasileiro. A pesquisa de campo foi necessária para identificar como os haitianos estão se mobilizando e articulando para garantir o acesso ao mundo do trabalho. Por isso, evidenciamos que apesar da queda nas contratações formais, eles se organizam em rede solidárias para garantir a permanência, a sobrevivência e as condições de vida em terra migratória.

\section{2 - A intrínseca relação entre comunicação e consumo}

Baccega $(2015$, p. 21) reconhece a complexidade do encontro entre comunicação e consumo. Mesmo que esses conceitos sejam intrínsecos, "os sentidos se ressignificam e a capacidade de pensar criticamente a realidade obriga a ter competência para selecionar informações e inter-relacioná-las produzindo conhecimentos".

O conhecimento produzido é indispensável para favorecer a criticidade dos sujeitos. Gomes (1997, p. 13) afirma que na comunicação, "[...] há sempre alguém tentando entrar em contato com alguém", por diversas razões e motivos. Bordenave $(2006$, p. 19) reforça essa ideia ao afirmar que a comunicação se confunde com a nossa própria existência, pois "[...] temos tanta consciência de que comunicamos quanto de que respiramos ou andamos" e, nessa lógica, podemos acrescentar o consumo de bens materiais e culturais enquanto pertencimento à sociedade.

Ao fortalecer a ideia de que a comunicação é um dos pilares na sociedade de consumo, estamos afirmando que ela é essencial na vida humana; concordamos que o conviver implica na co-participação dos sujeitos tornando comuns as experiências concretas e, ao mesmo tempo pertencendo ao mundo do outro, pois, como destaca Freire (1997, p. 66), o universo humano "é um mundo de comunicação". O mundo de comunicação pensado por Freire (1997) pode ser atualizado, como denomina Baccega (2013) de sociedade da informação, de consumo. Ou seja, esse mundo de comunicação em que o sujeito está inserido implica na reciprocidade (FREIRE, 1997), nos compartilhamentos de informações que podem gerar vínculos ou não. $O$ que dá sustentação para a reciprocidade, socialização e compartilhamentos entre as pessoas é o diálogo, mesmo que ocorra através das técnicas e nas plataformas digitais. Sem o diálogo não há comunicação, pois, de acordo com Freire (1997, p. 67), o que "[...] caracteriza a comunicação enquanto este comunicar comunicando-se, é que ela é diálogo, assim como o diálogo é comunicativo." 
Vincular o diálogo à comunicação e ao consumo é ligá-la à cultura, compreendendo a cultura como algo imanente ao ser humano, sendo assim, cada sujeito carrega consigo mesmo uma imensa carga cultural.

Daí a importância do diálogo, pois é no processo dialógico que as pessoas têm a possibilidade de compartilhar desejos, decisões, satisfações; socializar informações, produtos e serviços e tornar disponíveis os bens materiais e simbólicos aos sujeitos. Desse modo, a comunicação e o consumo podem ser entendidos como um processo colaborativo entre os sujeitos e também remetem à ideia de trocas, socialização e pertencimento. Para Duarte (2003), o pertencimento dos sujeitos aos lugares sociais abarca todas as dimensões da comunicação, pois

[...] para que algo seja comum a um grupo, para que haja comunhão, para tornar um pensamento comum, os envolvidos inevitavelmente têm de estar em relação. Estar em relação implica a emergência de uma superfície comum de troca, ou uma zona de encontro de percepções dos emissores e receptores (DUARTE, 2003, p. 46).

Percebe-se que emissores e receptores não podem ser considerados seres isolados. São seres de relações que pertencem aos espaços socioculturais construídos na sociedade. Nessa dimensão, entende-se o consumo como uma construção social. Para Mundel (2016, p.30) "o consumo traduz as relações sociais e produz sentido sobre cada indivíduo e sua posição social".

Nessa linha de pensamento, Abujamra (2016, p. 184) diz que o consumo "ao longo da humanidade sempre esteve atrelado não só à satisfação das necessidades biológicas, mas em todos os sentidos, às representações dos desejos e às aspirações humanas no plano do simbólico". É importante perceber que os bens que proporcionam satisfações biológicas e simbólicas servem para enviar e receber mensagens.

Isso demonstra, como indica Abujamra (2016, p. 185), que o "cerne da noção de consumo não converge na materialidade dos objetos consumidos, mas, sobretudo, na produção de sentidos que o consumo desses objetos expressa e representa ao gerar significados".

A produção de sentido pressupõe estabelecer relações. Ou seja, as pessoas não estão solitárias na sociedade de consumo. Apesar de que, na sociedade de consumo, como afirma Baccega $(2013$, p.18) a duração "é substituída pela transitoriedade, o durável pela permanente novidade, o estar em movimento é mais importante que adquirir e possuir bens".

Nessa dimensão, o pressuposto da sociedade de consumo "não é levar os sujeitos ao consumo de modo a satisfazer suas necessidades, reais ou imaginárias, mas sim transformar o próprio consumidor em mercadoria, um produto consumível" (BACCEGA, 2013, p. 18). 
No cotidiano das práticas sociais, os sujeitos críticos são aqueles que, como afirma Duarte (2003, p. 47), não obtêm "[...] concordância total com os enunciados envolvidos na troca". Passamos a perceber a construção da cidadania e o processo de consumo como um conjunto de comportamentos, entendido sim como um fenômeno complexo, mas que "envolve as relações socioculturais e se consubstancia num sistema simbólico, amplificado pelos meios de comunicação" (CARRASCOZA, 2016, p. 7).

\section{1 - Essencialidade do trabalho no processo migratório}

O trabalho é uma atividade central na vida das pessoas e, mais do que nunca somos dependentes dele para manter a nossa sobrevivência num mundo em que a lógica capitalista visa acentuar as desigualdades, promover a competitividade, as mobilidades, as relações individualistas e, com isso, os postos de trabalho se tornam transitórios, instáveis, precários e inexistente para um contingente cada vez maior da população.

Braga (2012) problematiza a natureza do trabalho centrando esforço para dimensionar a política do precariado. Ele se apoia na sociologia crítica do trabalho e tece olhares a partir das décadas de 1950 e 1960, por compreender que nesse período começam os grandes desafios da periferia capitalista. Para Braga (2012, p. 44) "o atraso brasileiro forjou as bases políticas da relação entre a sociologia e a classe operária ao longo desse período". Ou seja, o estado desenvolvimentista do pós-guerra e o coletivo empresarial não apenas se apoiaram em um ambíguo compromisso social com os trabalhadores e, vale lembrar que nesse período o Brasil estava acolhendo diversos migrantes, que viviam em condições de trabalho precarizados, como também estimularam a imaginação das pessoas a trabalharem cada vez mais, com isso, elas deveriam almejar a mobilidade social. Entretanto, a pressão empresarial era e continua sendo outra. Eles querem maior produtividade e "anular a distância históricocultural existente entre as sociedades subdesenvolvidas e o capitalismo avançado" (BRAGA, 2012, p.126).

Esse processo de estruturação do capitalismo que se desenvolveu e continua a se expandir em escala global, gera informalização da força vital do trabalho e faz ampliar as condições de precarização dos trabalhadores. Antunes (2013, p. 14) entende que

uma análise do capitalismo atual nos obriga a compreender que as formas vigentes de valorização do valor trazem embutidos novos meios geradores de trabalho excedente, ao mesmo tempo em que expulsam da produção uma infinitude de trabalhadores que se tornou sobrantes, descartáveis e desempregados (ANTUNES, 2013, p. 14). 
Para Antunes (2013, p. 15), a informalidade são os sucessivos "contratos temporários, sem estabilidade, sem registro em carteira, trabalhando dentro ou fora do espaço produtivo das empresas, quer em atividades mais instáveis ou temporárias, quer sob a ameaça direta do desemprego". E, o autor tece algumas classificações da informalidade vivenciadas pelos trabalhadores no Brasil. 1) Trabalhador informal tradicional. Identifica-o como tendo baixa qualificação e a sua força vital do trabalho contribui para obter renda; 2) Trabalhador informal menos instável. São pessoas que possuem um mínimo de conhecimento profissional e conhecedoras da área de atuação; 3) Trabalhador informal mais instável. Pessoas com baixa qualificação que são contratadas por tempo determinado e recebem a sua remuneração a partir do serviço realizado. É importante destacar que os trabalhadores mais instáveis podem ser subempregados pelos trabalhadores menos instáveis. Entretanto, essas atividades fazem parte das condições de trabalho precarizados; 4) Trabalhador ocasional ou temporário. São pessoas que desempenham atividades laborais enquanto estão desempregados, os chamados "bicos", nas palavras de Antunes (2013, p. 16) "ora estão desempregados, ora são absorvidos pelas formas de trabalho precário".

A partir dessas classificações, constata-se que a informalidade e as formas de acesso do trabalhador nessas atividades são desempenhadas em condições precárias. Inclui-se nessa dinâmica a baixa remuneração, em muitos casos, as jornadas de trabalho ampliadas e em diversas circunstâncias os trabalhadores não têm como garantia o acesso aos direitos sociais e civis.

Outra questão que merece ser problematizada é a ruptura institucional, não só do ponto de vista das contratações formais, com registro, sendo observadas as leis trabalhistas que regulam a força do trabalho inclusive com garantias, tais como: férias, décimo terceiro salário e outros, mas também, a ruptura com as formas de trabalho desprovidas de direitos (STANDING, 2015). E aqui podemos incluir os trabalhadores imigrantes que exercem as suas funções com as jornadas de trabalho expandidas, em horários desconfortáveis, precedência em horários noturnos e nos finais de semana.

Além disso, o exercício profissional dos imigrantes também é marcado por discriminações não só no local de trabalho, mas também no acesso às dependências deste local, na rua, no bairro onde moram, na roda de conversa. Sobre isso, Antunes (2013, p. 20) alerta que os imigrantes são "discriminados, mas não resignados, eles são parte integrantes da classe-que-vive-do-trabalho, exprimindo a vontade de melhorar as próprias condições de vida por meio do trabalho". Entretanto, os imigrantes para fazer frente à essa condição de trabalho, informalidade e precarização, eles se articulam em redes e, em diversos casos, através das tecnologias com intuito de orientar, informar, solidarizar, 
estabelecendo vínculos para superar algumas situações de dominação, exploração e violação de direitos sociais e trabalhistas.

Portanto, essas experiências de comunicação, consumo, trabalho, desemprego, informalidade e migração são pautas recorrentes na mídia. Por isso, compreender o trabalho e o consumo como possibilidade de organização e interação social é dar centralidade ao processo de informação, com acesso ao mundo do trabalho, bem como aos bens e serviços. Ressalta-se, com isso, que os recursos tecnológicos são instrumentos criativos importantes para unir as redes solidárias. Com isso, temos presente os três registros, apontados por Kamper (1998) em que as pessoas estão ligadas: o mundo real que se articula com o corpo, o simbólico que se liga com a linguagem e o imaginário que se liga aos sonhos e aos projetos de vida.

\section{3 - Mobilização dos haitianos para superar as dificuldades}

O Brasil não era a principal rota no fluxo migratório dos haitianos. Após, o terremoto de 2010, esse cenário, aos poucos se altera muito em razão das mensagens divulgadas e compartilhadas sobre o Brasil como sendo um país hospitaleiro, acolhedor, sem discriminação racial, alegre, próspero e abundante em postos de trabalho. Nesse primeiro momento, a comunicação humana foi fundamental na construção do imaginário positivo de um país que podia servir de referência para a imigração. O haitiano Dondon ${ }^{1}$, formado em contabilidade, relatou que: os militares brasileiros eram alegres. Falavam de futebol, das coisas boas que haviam no Brasil e muitos compatriotas ficaram interessados em conhecer. E, acrescenta: passamos a assistir jogos e novelas brasileiras.

Vale ressaltar que essas coisas boas comunicadas pelos militares eram as oportunidades de trabalho, já que o Brasil sediaria dois grandes eventos internacionais: Copa do Mundo e Jogos Olímpicos. Tanto é que o haitiano Ennery disse: cheguei aqui conhecendo os jogadores porque fui incentivado a assistir jogos do Corinthians e hoje quando ligo para minha família eu digo 'sou vizinho de todos eles'. Ele está há três anos em São Paulo, acompanhou as festividades da Copa do Mundo pela televisão e ainda não teve a oportunidade de participar de eventos esportivos no estádio do time pelo qual aprendeu a torcer. Mas, mantém o desejo de conhecer porque: passei a gostar do Brasil pelo que falavam do futebol. E, o haitiano Milot confirma: assistia futebol $e$ novela. No Brasil, passo pelos lugares e imagino: já vi essa imagem na novela e me sinto bem.

Neste caso, a comunicação humana e mediada (THOMPSON, 1998) se solidificam a partir das interações, das trocas que se realiza em conjunto e num ato dialógico de partilha e de comunhão. Evidentemente que essas mensagens de otimismo em relação ao Brasil são reforçadas pela grande mídia junto à comunidade internacional quando se veicula as partidas de futebol. Por exemplo, 
a seleção brasileira realizou um jogo amistoso contra a seleção do Haiti, em agosto de 2004. Nessa ocasião, a delegação permaneceu apenas cinco horas no país, tempo suficiente para reforçar o sentimento de alegria, acolhida e solidariedade.

Essa situação, envolvendo as socializações das mensagens comunicacionais na construção de um imaginário positivo do país, nos faz articular com um dos poemas de Machado de Assis. Ele ressaltava que existiam dois Brasis, o oficial e o real. Pode-se dizer, nos dias atuais, que no Brasil oficial, expressa-se o caricato, as superficialidades, a ordem e o faz de conta. Já no Brasil real é a manifestação da vida cotidiana, enxerga-se as exclusões, as ausências de políticas públicas, falta de acesso à moradia, à saúde, à educação, ou seja, são as especificidades reais que não se divulgam. Entretanto, elas só são reveladas quando as pessoas entram em contato com esse universo.

E, o primeiro contato de muitos haitianos com a realidade migratória foi a saga para se chegar a fronteira na região norte do Brasil. Os haitianos recebiam dos coiotes ${ }^{2}$ um panfleto com o trajeto apresentando um percurso a partir do Panamá. Estimavam a travessia em três dias e meio. Na realidade, considerando os trajetos a pé, as longas esperas dos navios, barcos, balsa e dos veículos automotivos, durava entre oito a quinze dias.

É importante dizer que no processo das trocas comunicacionais, as mensagens compartilhadas sobre o Brasil eram marcadas pelo discurso de facilidade, agilidade e economicidade tanto de recursos financeiros quanto do tempo. É o que revela a haitiana La Victoire. No período do deslocamento ela estava grávida, por isso demorou mais de um mês viajando. Ela conta: [...] passei por muitas dificuldades até chegar ao Brasil, pensei que iria perder meu bebê, jamais pensei que seria assim. Fiquei desesperada com as informações erradas, com a burocracia e com a enganação que sofri porque quando a gente carrega uma vida dentro da gente, a gente pensa muito mais.

Percebe-se que, nesses casos, a comunicação serviu apenas como uma transmissão de mensagens. Entretanto, ela deve representar interação, atenção à presença de interlocutores, ou seja, aquilo que França $(2001$, p. 15) afirma: representar "à intervenção de sujeitos sociais desempenhando papéis, envolvidos em processos de produção e interpretação de sentidos, mais do que simples emissores e receptores".

Outro fato marcante para os haitianos foi o acesso aos municípios de Tabatinga/AM ou em Brasileia no estado do Acre. La Victoire optou pelo estado do Acre e diz: cheguei cansada, sem saber para onde ir, sem ter o que comer e nem onde dormir. Apesar da indefinição peculiar de quem chega a um país desconhecido, a situação agrava-se porque os haitianos são informados de que no Brasil há acolhida, alimentação e moradia sem custos. Isso porque havia um esforço do governo do Estado e das Instituições religiosas, dentre elas, o Serviço Pastoral dos Migrantes, coordenado pelos padres Carlistas, em acolher e auxiliar nos procedimentos de documentação aos imigrantes, uma vez que poucos 
haitianos chegaram com o visto, e, encaminhá-los para as cidades onde teriam maiores oportunidades de trabalho.

É importante ressaltar que para obter o Visto há que se enfrentar um processo burocrático e dispêndio de recursos financeiros. Por isso, os haitianos, a maioria, pedem refúgio junto à Polícia Federal (PF). Com o protocolo e a carta de autorização da PF estão autorizados a solicitar o CPF e a Carteira de Trabalho. Ou seja, eles podem trabalhar, conseguir recursos e lutar para obter o Visto Humanitário ${ }^{3}$. Em relação ao pedido de refúgio, há um acordo entre o Comitê Nacional para Refugiados (CONARE) e o Conselho Nacional das Migrações (CNIg) para analisar os pedidos dos haitianos e garantir sua permanência. Mas, com o passar do tempo a solicitação é indeferida. Todavia, eles ganham tempo para conseguir o Visto. Em todas essas situações, as trocas comunicacionais estão presentes. E, em muitos momentos, a ação comunicativa é partilhada individualmente ou no coletivo. Como expressa Elaine Cristina ${ }^{4}$, enfermeira da Missão Paz: às vezes informamos os procedimentos no coletivo, mas [sic] pela dificuldade com o idioma, temos que falar com cada um. Isso demonstra que a comunicação humana é fundamental no processo migratório e na formação de rede migratória e solidária, uma vez que as informações são socializadas, uns com os outros.

Outro aspecto é que a maioria dos haitianos chega sem recursos financeiros e sem o domínio da língua portuguesa. A chegada dos haitianos na região, mesmo para as Instituições que atuam na acolhida de imigrantes, não era esperada e nem havia estrutura organizacional para atender o fluxo contínuo de pessoas, predominantemente homens, entre 18 a 65 anos, sendo que a concentração da faixa etária dos homens é de 32 anos e das mulheres 33 anos. Costa (2016) relata que em março de 2010, chegaram os primeiros haitianos que, transportados em uma Kombi, foram acolhidos na Casa do Migrante em Manaus-AM. Porém, na semana seguinte, além da Kombi, foram utilizados mais três carros e a Casa do Migrante já não comportava mais pessoas. Os padres tiveram que alugar outras casas na capital amazônica, pedir auxílio às paróquias, às congregações, ONGs para acolher adequadamente os haitianos.

Vejamos na Tabela 1 a dinâmica, mês a mês, do fluxo migratório na cidade de Tabatinga no ano de 2013.

Tabela 1: Fluxo migratório na cidade de Tabatinga (2013)

\begin{tabular}{|l|l|l|l|l|l|l|l|l|l|l|l|l|}
\hline Jan & Fev & Mar & Abr & Mai & Jun & Jul & Ago & Set & Out & Nov & Dez & Total \\
\hline 140 & 180 & 102 & 160 & 150 & 85 & 92 & 102 & 108 & 281 & 207 & 227 & 1.835 \\
\hline
\end{tabular}

Fonte: Costa (2016) 
A comunicação compartilhada fortaleceu as interações sociais e serviram para organizar os processos de acolhida dos haitianos, disponibilizando informações para solicitar os documentos oficiais e contribuiu para informar aos sujeitos a respeito das cidades com mais oportunidade na área do emprego. Com essas informações, os haitianos seguiram adiante. Cerca de cinquenta por cento, optaram pelo estado de São Paulo. E, de acordo com o relatório da Missão Paz - São Paulo sobre o perfil dos haitianos acolhidos, eles saíam do município de Brasileia/ AC e demoravam em média 20 dias em deslocamento até chegar a São Paulo. Consta no relatório que um haitiano demorou 290 dias para chegar até a capital paulista (MISSÃO PAZ, 2015).

A haitiana La Victoire conta que ela não sabia qual destino seguir: fui aconselhada a vir para São Paulo. Os compatriotas que conheci quando cheguei, a maioria vinha para cá, vim também porque pelo menos já conhecia alguém. Conhecer pessoas e participar de uma rede migratória foi fundamental para La Victoire. Ela, há mais de ano no Brasil, tem dificuldades em aprender o idioma e não conquistou o espaço laboral remunerado. De acordo com ela: ainda não trabalhei ganhando nenhum dia aqui. Para La Victoire, mulher e mãe de bebê é excluída: porque quando vou pedir emprego, de diarista, de limpeza, quando me perguntam se tenho criança e falo que tenho um bebê, nem termina a conversa. Por isso, a rede de apoio é fundamental pois, La Victoire conta que ficou três meses na Casa do Migrante da Missão Paz - São Paulo, mas teve que sair porque, vencidos os três meses, período em que os imigrantes podem se organizar, é preciso buscar outro local de hospedagem ou de moradia. Atualmente ela mora escondida com um amigo num quarto no bairro Liberdade, pois, de acordo com La Victoire, a dona da pensão cobra o aluguel por pessoa e eu não tenho como pagar.

\section{1 - Haitianos e o direito ao trabalho}

É importante ressaltar que o acesso dos haitianos às informações sobre as vagas de emprego ocorre através dos murais informativos; da comunicação interpessoal; das publicações nos grupos de whatsapp e no facebook. Nesse sentido, o trabalho, como uma instituição social, é uma das principais vigas de sustentação, manutenção e sobrevivência das pessoas, ainda mais quando se vive num sistema capitalista.

Antunes (2013) apresenta três impactos, os quais influenciam de modo decisivo na força vital do trabalho e, mais ainda, o trabalhador imigrante. São eles: a substituição do trabalho humano pelo trabalho realizado por equipamentos cada vez mais sofisticados e por estruturas de comunicação eficazes; o impacto político, com as ações neoliberais em que se promove a 
falência do Estado, fazendo com que as pessoas criem o seu próprio posto de trabalho e a flexibilização da força do trabalho. Ou seja, mudam-se os padrões produtivos e de consumo para exigir novas competências, habilidades e desempenho profissional.

No fluxo migratório há aproximações com esses elementos. Os haitianos veem no trabalho a possibilidade para melhorar as condições da sua vida e de familiares que deixaram no país de origem. Nos relatos, os haitianos esclarecem a importância do trabalho, como menciona o jovem Pierre Payen: saí do meu país em busca de trabalho. Lá o desemprego é muito alto, não tem emprego para todo mundo, por isso, vim tentar a sorte no Brasil. E todos diziam: 'lá sobra emprego'.

Pierre Payen, 23 anos, chegou ao Brasil na segunda leva do fluxo imigratório. Considera-se que a primeira leva tenha chegado entre 2010 a 2013, em que o processo de ingresso no país era através da fronteira na Região Norte. As pessoas que ingressaram no país no final de 2013, início da segunda leva, já chegavam com o visto humanitário. Nesse caso, o percurso era: Haiti ou República Dominicana, Panamá, São Paulo. Pierre Payen fez esse percurso. Com os documentos em mãos e com ajuda dos primos, na primeira semana já começou a trabalhar na área da construção civil e diz: gosto do trabalho. Agora preciso fazer um curso de pintor para mudar de setor e ganhar um pouquinho mais.

Desse modo, a questão - da qualificação, da precarização e flexibilização - atinge diretamente o trabalhador imigrante. No caso dos haitianos, mesmo àqueles que têm estudos para atuarem em setores que requer qualificações, não há reconhecimento das suas potencialidades ou competências. A Missão Paz - São Paulo publicou, em 2015, o perfil dos haitianos atendidos pela Instituição. A profissão que as mulheres declararam exercer foi a de comerciante. Entretanto, $12 \%$ delas declararam ter profissão de: administradora, contabilista e enfermeira. Em relação aos homens, destacam-se as profissões que se exigem pouca qualificação: pedreiro, agricultor, comerciante e caminhoneiro. E há profissionais qualificados, tais como: professor, jornalista, contador, administrador, advogado, fotógrafo. O fato importante a ser considerado é que diversos haitianos se declararam estudantes. Isso demonstra que eles começaram a formação no Haiti e que desejam concluir ou revalidar os diplomas em Instituições brasileiras. É o caso do haitiano Belladère, professor e teólogo. Mas, no Brasil teve dificuldade em revalidar o diploma. Ele está estudando novamente o curso de teologia. Enquanto isso, para se manter e ajudar seus familiares, encontrou trabalho na área da construção civil.

Nos relatos dos entrevistados, percebe-se que os haitianos com mão de obra qualificada, na maioria dos casos, têm dificuldades de se inserirem na sua área de formação. De certo modo, as empresas brasileiras estão desperdiçando 
a mão de obra qualificada, o que seria mais vantajosa para a economia e para o desenvolvimento dos setores produtivos. Isto configura uma dificuldade de perceber o haitiano como um sujeito em potencial, posto que a maior parte dos trabalhadores haitianos atua no setor de serviços, especialmente na construção civil, frigoríficos, restaurantes, setor alimentícios; com longas jornadas de trabalho e com faixa de renda de até dois salários mínimos (HANDERSON, 2016).

Em entrevista com a psicóloga Berenice Young ${ }^{5}$ da Missão Paz, ela relatou que os haitianos chegaram no Brasil entusiasmados para trabalhar. Era bonito, a gente via o entusiasmo dos haitianos, a alegria deles, mesmo diante da viagem cansativa. Berenice Young recorda também que os haitianos com qualificação contratados para exercer funções com pouca instrução e escolaridade, alguns não conseguiram se adaptar. Essas situações podem ser constatadas na Tabela 2 sistematizada, contendo informações das ocupações no país de origem e a situação atual: desemprego, trabalho formal e informal.

\section{Tabela 2: Entrevistados}

\begin{tabular}{|c|c|c|c|c|c|c|c|}
\hline Nome & Idade & $\begin{array}{c}\text { Ocupação } \\
\text { antes da } \\
\text { chegada ao } \\
\text { Brasil }\end{array}$ & Escolaridade & $\begin{array}{l}\text { Data de } \\
\text { chegada } \\
\text { ao Brasil }\end{array}$ & $\begin{array}{l}\text { Ocupação } \\
\text { no Brasil }\end{array}$ & Situação Atual & Filhos \\
\hline Dondon & 30 & Contador & $\begin{array}{l}\text { Ensino } \\
\text { superior } \\
\text { completo }\end{array}$ & 2013 & Garçom & Desempregado & 0 \\
\hline Pétionville & 26 & Vendedor & $\begin{array}{l}\text { Ensino médio } \\
\text { completo }\end{array}$ & 2014 & $\begin{array}{l}\text { Indústria de } \\
\text { montagem }\end{array}$ & $\begin{array}{l}\text { Trabalho } \\
\text { informal }\end{array}$ & 0 \\
\hline Ennery & 34 & Administrador & $\begin{array}{l}\text { Ensino } \\
\text { superior } \\
\text { completo }\end{array}$ & 2013 & $\begin{array}{l}\text { Servente de } \\
\text { pedreiro }\end{array}$ & Trabalho formal & 2 \\
\hline $\begin{array}{l}\text { Pierre } \\
\text { Payen }\end{array}$ & 20 & Servente & $\begin{array}{l}\text { Ensino médio } \\
\text { completo }\end{array}$ & 2016 & $\begin{array}{l}\text { Servente de } \\
\text { pedreiro }\end{array}$ & Trabalho formal & 0 \\
\hline Milot & 35 & Pedreiro & $\begin{array}{l}\text { Ensino médio } \\
\text { completo }\end{array}$ & 2014 & $\begin{array}{c}\text { Servente de } \\
\text { pedreiro }\end{array}$ & $\begin{array}{l}\text { Trabalho } \\
\text { informal }\end{array}$ & 3 \\
\hline Montrouis & 28 & Vendedor & $\begin{array}{c}\text { Ensino } \\
\text { superior } \\
\text { incompleto }\end{array}$ & 2014 & $\begin{array}{c}\text { Entrevista } \\
\text { de emprego }\end{array}$ & Desempregado & 1 \\
\hline Belladére & 39 & Professor & $\begin{array}{l}\text { Ensino } \\
\text { Superior }\end{array}$ & 2013 & $\begin{array}{l}\text { Servente de } \\
\text { pedreiro }\end{array}$ & Desempregado & 1 \\
\hline Saint-Marc & 38 & Motorista & Ensino médio & 2015 & $\begin{array}{l}\text { Servente de } \\
\text { pedreiro }\end{array}$ & $\begin{array}{l}\text { Trabalho } \\
\text { informal }\end{array}$ & 2 \\
\hline La Victorie & 28 & Doméstica & Ensino médio & 2014 & & Desempregada & 1 \\
\hline
\end{tabular}

Fonte: Elaboração própria 
Na Tabela 2, verifica-se o perfil dos entrevistados e seu tipo de inserção no mundo do trabalho. 0 haitiano Conge, 26 anos, contador, disse: Cheguei muito bem aqui no Brasil. Só precisava trabalhar. Encontrei trabalho como cuidador. A proposta era boa, dormir no trabalho, com alimentação e salário de dois mil reais. Aceitei. No local fiquei sabendo que era para cuidar de um jovem de 18 anos, com problemas mentais. Esse jovem, à noite, tinha agitações, convulsões e eu não podia dormir nem de dia e nem de noite. Passou um mês eu perdi o controle de mim mesmo. Fiquei doente, fui internado no hospital e sai do emprego sem receber meus direitos. Agora estou doente, tomando medicação controlada e [estou]desempregado.

Em conversa com outros haitianos que têm ensino superior completo e com curso técnico profissionalizante, muitos deles dizem que no exercício diário das atividades não são tratados com respeito. Montrouis, que trabalhou três meses em um frigorifico na cidade de Caxias do Sul/RS, diz: o tratamento de desrespeito era tanto dos superiores quanto dos colegas de trabalho, além do salário que é pouco. Por isso resolvi sair e trabalhar para mim mesmo. Ser o meu próprio patrão.

A forma como são tratados no ambiente de trabalho faz com que os haitianos reajam de diversos modos, mesmo precisando do trabalho. Alguns se silenciam, como diz Milot: eu faço de conta que não é comigo, o meu chefe mesmo diz, releve. E e eu relevo. Outros deixam de ir ao trabalho, abandonando o emprego e outros discutem com as pessoas que os desrespeitam. Vale ressaltar que é próprio dos haitianos a resistência, Belladère explica: somos resistentes. $E$, se pudéssemos iríamos às ruas protestar contra essas situações, mas se a gente fizer isso, seremos deportados.

A situação é mais complexa para os desempregados e que ao mesmo tempo entram na dimensão conceitual da informalidade proposta por Antunes (2013), como sendo o trabalhador formal tradicional em condições de precarização. Vim pro Brasil faz 9 meses, e eu não gosto daqui porque eu gastei muito dinheiro para vir até aqui e não tenho trabalho. Eu estava trabalhando mas "ele" (ele, no caso é o patrão) não queria me pagar. Disse que pagaria $R \$ 1.200,00$, pagava $R \$$ 800,00 , e tinha que fazer hora extra e não pagava, numa empresa de fazer caixa d'agua. Tem muita gente brasileira que faz fiado comigo... e eu não podia comer as comidas "dele". (Saint-Marc)

Atualmente, o recurso financeiro que ele obtém é através de um "bico", trabalho ocasional ou temporário (ANTUNES, 2013), com costuras e reparos para fábricas da região, e atua em frente à igreja Nossa Senhora da Paz diariamente, o que é ilegal. Mas, segundo ele, fica à espera de outras oportunidades. Ele desenvolve essa atividade numa tentativa de se manter e revela: o que eu ganho é pouco. Essa atividade, com ganho incerto não se consegue juntar dinheiro para enviar remessas aos familiares e muito menos para retornar ao país de origem.

Se os homens têm dificuldades no acesso ao emprego, as mulheres enfrentam mais desafios. É o caso de La Victoire. Ela narra que se comunicava 
com um primo pelo aplicativo WhatsApp e ele dizia que no Brasil seria mais fácil conseguir emprego. La Victoire se posiciona como uma trabalhadora informal, mais instávelpois, ela lava e passa as roupas dos haitianos que estão empregados formalmente. Quem me ajuda são os meus companheiros haitianos que conheci aqui. Inclusive moro com um haitiano que me esconde no quarto dele para a dona do apartamento não cobrar a mais no aluguel. Em retribuição lavo e passo a roupa dele e dos outros que moram no prédio, ao todo são oito. (La Victoire).

La Victoire deseja retornar para o Haiti e fez questão de ressaltar: quero voltar com certeza, mostrando o desapontamento frente as ausências de oportunidades vivenciadas no Brasil. A situação da haitiana revela que muitos dos imigrantes que vivem no país possuem formação acadêmica, cursos profissionalizantes, outros têm pouca escolaridade. O fato é que os imigrantes qualificados ou não encontram dificuldades na conquista de emprego. Tonhati et al (2016, p. 39) nos informam que entre 2010 a 2014 havia 30.484 haitianos inseridos no mercado de trabalho formal, com pessoas na faixa etária entre 20 a 39 anos ativas e com jornada de trabalho de 40 a 45 horas semanais (TONHATI et al, 2016, p. 55).

Isso ocorreu com o haitiano Pétionville pela não aceitação da sua condição e cor de pele. Ele acompanhou um grupo de imigrante que estava vindo do Acre para São Paulo, chegou na Barra Funda e um dos imigrantes disse: 'vamos para Santa Catarina. Ele pensou: eu vou onde esse irmão ir [for]. Considera todos que estão na mesma condição que ele, um irmão. Foi contratado por uma indústria de montagem de geladeira da marca Cônsul. Ele relembra: ganhava $R \$ 800$ reais, mais transporte. Esse valor era para pagar aluguel, alimentação e enviar uma quantia para casa. Mas não sobrava.

Ele trabalhou sete meses e relata que sofria muita discriminação em Santa Catarina. Ele comentou que pegava o ônibus, sentava em uma poltrona e o outro ficava vazio: ninguém sentava, podia estar lotado o ônibus, mas as pessoas não sentavam. Eu observo, eu sinto, não precisavam falar, eu sentia que era por conta da minha cor de pele. Por isso, decidi sair do emprego, já que não ganhava nem para me manter, e voltar para São Paulo.

Em São Paulo, sem vínculo laboral, ele decidiu montar uma banca na rua, próximo à entrada do terminal Grajaú, mas prefere morar no centro para não perder o vínculo com os demais haitianos. Ele disse: estiquei um pano azul escuro no chão e comecei a vender óculos, carregador e capa de celulares, fone de ouvido. $E$, acrescenta: no início era eu, um peruano, um africano. E, como viram que a gente estava vendendo bem, os brasileiros também montaram uma banca aqui.

Sobre as vendas dos produtos, ele tece uma análise de conjuntura. Quando cheguei aqui para vender, o Brasil estava bom, as pessoas compravam mais e agora está ruim. As vendas não estão boas, mas espero que melhore. Isso é um indicativo de que a situação financeira pela qual atravessa o país está tendo impacto decisivo na vida cotidiana das pessoas. 
A informalidade, nesse contexto, por um lado, assegura uma rede migratória com tendências a condições precárias, por outro, há controle dos agentes do Estado, da repressão policial principalmente, quando os setores econômicos se sentem ameados na sua lucratividade. Pétionville afirma: É forte a ação da polícia. A polícia já tomou um lote de produto meu e isso dificulta ainda mais agente honrar os compromissos. Vou te contar, quando comecei a vender os produtos, ainda não tinha barraca. Estendia um lençol no chão e espalhava os produtos. E, um dia, passou o ônibus por cima, levou tudo, acabou com tudo. Isso desanima porque só quero ter a oportunidade de trabalhar.

Com esse forte desejo de trabalhar, Pétionville mantém atenção aos produtos, aos clientes que passam e ao celular. Vez ou outra, apalpava o bolso da jaqueta para conferir o aparelho. E, mesmo conversando, ele manteve um fone no ouvido esquerdo e o outro ficou suspenso próximo ao peito. Nesse sentido, os imigrantes economicamente mais vulneráveis se mantêm unidos e solidários para se preservarem. Pétionville diz: Aqui um protege o outro. Um ajuda o outro. Ele cita como exemplo, que cada dia é a vez de um fazer o almoço: enquanto o companheiro está fazendo a alimentação, os demais cuidam dos seus produtos, realizam as vendas. Assim, não pesa para ninguém.

Isso demonstra que a imigração haitiana é uma realidade no nosso país, com reflexos na acentuada dependência ao mundo do trabalho. Sendo que as condições sociais de permanência do imigrante, duradoura ou provisória (SAYAD, 1998), ficam condicionadas ao trabalho formal ou informal, mas ambos, enquanto força de trabalho, são marcadas pela vulnerabilidade, precarização e marginalização socioeconômica e cultural. Como ressalta Baitello Junior (2014), quanto mais se trabalha, menos vale o próprio trabalho principalmente por conta do descarte e da desvalorização das pessoas. 


\section{4 - Conclusão}

Constata-se neste estudo que comunicação e consumo são dimensões que se interligam. Não há como dissociá-los. Ainda mais nos dias atuais. Estamos imersos na sociedade da comunicação e do consumo (BACCEGA, 2013). A comunicação é um espaço aberto para trocas, partilhas que fomenta as interações sensíveis, singulares, alegres, livres e autônomas entre os sujeitos. Comunicação e consumo geram vínculos.

Neste estudo, a comunicação face a face e as linguagens corporais dos haitianos se apresentaram como ponto de partida na consolidação do fluxo migratório. Potencializadas pela comunicação mediada e quase mediada (THOMPSON, 1998), ou seja, os haitianos recebiam informações nos alojamentos, nas reuniões coletivas, nos encontros festivos ou através de murais informativos e telefonemas. Eles também passaram a usar e gerar conteúdos nas páginas do facebook, no aplicativo whatsapp, na plataforma de canal youtube e através da arte musical, dança e grafite.

A articulação desses elementos com comunicação, consumo e migrações partiu das práticas e interações cotidianas. Desde ler a mensagem sobre oferta de trabalho no mural fixado no salão de entrada da Missão Paz - São Paulo, socializar essa informação através da comunicação face a face ou pelas redes digitais, até, o protagonismo; criar espaços comunicacionais para informar os demais haitianos sobre: oportunidades de emprego, documentações, moradia, atendimento de saúde, eventos culturais, reuniões, mobilizações em solidariedade ao outro mais necessitado, de modo que essas informações produzam, negociem e circulem significados sociais (ARIZTÍA, 2016).

\section{Notas}

\footnotetext{
${ }^{1}$ Adotaremos, daqui em diante, os nomes das cidades haitianas como forma de preservar a identidade dos entrevistados e das entrevistadas.

${ }^{2}$ São pessoas que atravessam os imigrantes pelas áreas de fronteira, mediante pagamento.

${ }^{3} \mathrm{O}$ visto humanitário, válido por dois anos, foi publicado no dia 12 de janeiro de 2012 através da Resolução Normativa n 97 assinada pela presidenta Dilma Rousseff.

${ }^{4}$ Ela concedeu a entrevista no dia 22/09/2016.

${ }^{5}$ Entrevista concedida no dia 14/04/2017.
} 


\section{Referências}

ABUJAMRA, Marisa B. Portela. Consumo e suas representações na obra de Baudelaire: a expressão do espírito de um tempo. In. CARRASCOZA, João Anzanello. Laboratório do sensivel: comunicação, consumo e arte. Porto Alegre: Sulina, 2016.

ANTUNES, Ricardo. A nova morfologia do trabalho e suas principais tendências. In.: ANTUNES, Ricardo. Riqueza e miséria do trabalho no Brasil II. São Paulo: Boitempo, 2013. p. 13-28

ARIZTíA, Tomás. Classes médias e consumo: três enfoques de leitura a partir da sociologia. In.: COGO, Denise; ROCHA, Rose de Melo e HOFF, Tânia. O que é consumo: comunicação, dinâmicas produtivas e constituição de subjetividades. Porto Alegre: Sulina, 2016. p. 17-37.

BACCEGA, Maria Aparecida. Um panorama da intersecção comunicação e consumo. In.: TONDATO, Marcia Perecin e BACCEGA, Maria Aparecida. A telenovela nas relações de comunicação e consumo: diálogos Brasil e Portugal. Jundiaí, SP: Paco Editorial, 2013. p. 13-33.

BAITELLO JUNIOR, Norval. A era da iconofagia: reflexões sobre imagem, comunicação, mídia e cultura. São Paulo: Paulus, 2014.

BORDENAVE, Juan E. Díaz. O que é comunicação. 30. ed., São Paulo: Brasiliense, 2006.

BRAGA, Ruy. A política do precariado: do populismo à hegemonia lulista. São Paulo: Boitempo: USP, 2012.

CARRASCOZA, João Anzanello. Laboratório do sensivel: comunicação, consumo e arte. Porto Alegre: Sulina, 2016. p. 11-27.

COSTA, Gelmino. Memória da chegada de imigrantes haitianos a Manaus, 2010-2014: presença da Pastoral do Migrante. Caderno especial de migração, Centro de Estudos Migratórios, São Paulo, v.8, 2016. p. 1-84.

DUARTE, Eduardo. Por uma epistemologia da comunicação. In.: LOPES, Maria Immacolata Vassallo. Epistemologia da comunicação. São Paulo: Loyola, 2003.

FRANÇA, Vera. Paradigmas da comunicação: conhecer o que? Revista Ciberlegenda. Rio de Janeiro: UFF, edição especial, n.5, p.1-19, 2001.

FREIRE, Paulo. Extensão ou comunicação? ed.9, Rio de Janeiro, RJ, Paz e Terra, 1997.

GOMES, Pedro Gilberto. Comunicação social: filosofia, ética, política. São Leopoldo: Unisinos, 1997.

HANDERSON, Joseph. A historicidade da (e)imigração internacional haitiana: o Brasil como novo espaço migratório. Relatório Anual. Observatório das Migrações Internacionais. Brasília, DF: OBMigra, 2016. p. 83-104

KAMPER, Dietmar. O trabalho como vida. São Paulo: Annablume, 1998. 
MUNDEL, Jane de Freitas Misseno. O discurso do consumo "a seus pés": um estudo da narrativa publicitária de Havaianas a partir da retextualização da obra Abaporu. In. CARRASCOZA, João Anzanello. Laboratório do sensível: comunicação, consumo e arte. Porto Alegre: Sulina, 2016.

MISSÃO PAZ. Perfil dos haitianos acolhidos na Missão Paz em janeiro à julho de 2015. Relatório Missão Paz. São Paulo, v.1, p.1-20, 2015.

ROCHA, Rose de Melo e PERES-NETO, Luiz. Memória, comunicação e consumo: vestígios e prospecções. Porto Alegre: Sulina, 2015. p. 21-31.

SAYAD, Abdelmalek. A imigração ou os paradoxos da alteridade. São Paulo. EDUSP, 1998.

STANDING, Guy. O precariado: a nova classe perigosa. 1. ed., 2. reimp., Belo Horizonte: Autêntica, 2015.

THOMPSON, John B. A mídia e a modernidade: uma teoria social de mídia. Petrópolis: Vozes, 1998.

TONHATI, Tânia, CAVALCANTI, Leonardo, BOTEGA, Tuíta, OLIVEIRA, Antônio Tadeu. Os imigrantes haitianos no Brasil: a empregabilidade dos haitianos no mercado de trabalho brasileiro. Relatório Anual. Observatório das Migrações Internacionais. Brasília, DF: OBMigra 2016. p. 38-60.

ZAMBERLAM, Jurandir, CORSO, Giovanni, CIMADON, João Marcos e BOCCHI, Lauro. Os novos rostos da imigração no Brasil: haitianos no Rio Grande do Sul. Porto Alegre: Solidus, 2014. 


\title{
RESUMO
}

$\mathrm{O}$ artigo tem como objetivo debater comunicação, consumo, trabalho enquanto processo de mediação dos imigrantes haitianos em São Paulo e compreender de que forma os haitianos se articulam para superar as desvalorizações, a precarização e a informalidade, uma vez que muitos deles têm qualificações, mas desenvolvem atividades laborais aquém das suas formações profissionais. Com base em observação e entrevista em profundidade com os haitianos é possível constatar que eles mantêm as expectativas de acesso ao mundo do trabalho e o desejo de melhorar as condições de vida, sendo que para isso mobilizam-se em redes migratórias. Evidenciamos que os usos e as articulações, através da comunicação face a face e das plataformas digitais, ajudam a superar as situações de desvalorização da força vital do trabalho, garantindo a permanência, fortalecendo as lutas e melhorando as condições de vida.

Palavras-chave: comunicação, consumo, trabalho, migração, haitianos.

\begin{abstract}
The article aims to discuss communication, consumption, work as a process of mediation of Haitian immigrants in São Paulo and understand how Haitians articulate to overcome devaluations, precariousness and informality, since many of them have qualifications, but Work activities short of their professional training. Based on observation and in-depth interview with Haitians, it is possible to see that they maintain the expectations of access to the world of work and the desire to improve living conditions. For this, they mobilize themselves in a migrant and solidarity network. We show that uses and articulations, through face-to-face communication and digital platforms, help overcome situations of devaluation of the work force, guaranteeing permanence, strengthening struggles and improving living conditions.
\end{abstract}

Keywords: communication, consumption, job, migration, haitians. 